\title{
Endogenous endophthalmitis caused by group B streptococcus; case reports and review of 35 reported cases
}

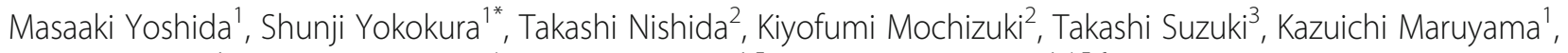
Takaaki Otomo ${ }^{1}$, Koji M. Nishiguchi ${ }^{4}$, Hiroshi Kunikata ${ }^{1,5}$ and Toru Nakazawa ${ }^{1,4,5,6}$

\begin{abstract}
Background: Group B streptococcus (GBS), a gram-positive coccus that occasionally causes neonatal sepsis or invasive infection in the elderly, has been considered a rare cause of endogenous bacterial endophthalmitis (EBE). However, the number of invasive GBS infections is increasing, particularly in elderly patients with underlying conditions such as diabetes mellitus (DM), cardiovascular disease and cancer. We report 6 cases of EBE caused by GBS and review the literature.

Methods: Retrospective case series and literature review.

Results: In the current case series, 6 eyes of 6 patients developed EBE caused by GBS. The average age was 73.5 years. The focus of infection included the urinary tract, cellulitis, arthritis, peritonitis, catheter-associated infection and endocarditis. Four patients had DM. While all 6 strains were sensitive to $\beta$-lactams (penicillins and cephems), 4 strains were resistant to levofloxacin (no data for 1 isolate). Each case was treated with the systemic antibiotic to which the individual strain was sensitive. All cases showed poor visual acuity at presentation (decimal visual acuity: less than 0.03). Vitrectomy with intravitreal antibiotics injection was performed in 4 cases. Visual acuity recovered in 4 cases and did not recover in 2 cases, even after vitrectomy. The literature review of 53 eyes of 41 patients revealed that $60 \%$ of eyes finally lost all vision, and death occurred in 2 cases. Initial visual acuity of less than counting fingers was associated with a final outcome of lost vision. Of 41 patients, 13 (32\%) had DM as an underlying medical condition. The most common extra-ocular infection focus was endocarditis (37\%).

Conclusions: DM is common in patients with EBE caused by GBS. While the 4 cases in the current report had a relatively good visual acuity outcome, despite poor initial visual acuity, the literature review indicated that EBE caused by GBS is generally a severe condition with a poor prognosis. The current study also indicates the importance of considering the possibility of endocarditis on encountering EBE caused by GBS.
\end{abstract}

Keywords: Endogenous bacterial endophthalmitis, Group B streptococcus (GBS, Streptococcus agalactiae), Endocarditis, Diabetes mellitus, Quinolone-resistant GBS

\footnotetext{
* Correspondence: yokokura@oph.med.tohoku.ac.jp

'Department of Ophthalmology, Tohoku University Graduate School of Medicine, 1-1, Seiryo-machi, Aoba-ku, Sendai, Miyagi 980-8574, Japan

Full list of author information is available at the end of the article
}

(C) The Author(s). 2020 Open Access This article is licensed under a Creative Commons Attribution 4.0 International License, which permits use, sharing, adaptation, distribution and reproduction in any medium or format, as long as you give appropriate credit to the original author(s) and the source, provide a link to the Creative Commons licence, and indicate if changes were made. The images or other third party material in this article are included in the article's Creative Commons. licence, unless indicated otherwise in a credit line to the material. If material is not included in the article's Creative Commons licence and your intended use is not permitted by statutory regulation or exceeds the permitted use, you will need to obtain permission directly from the copyright holder. To view a copy of this licence, visit http://creativecommons.org/licenses/by/4.0/ The Creative Commons Public Domain Dedication waiver (http://creativecommons.org/publicdomain/zero/1.0/) applies to the data made available in this article, unless otherwise stated in a credit line to the data. 


\section{Background}

Endogenous bacterial endophthalmitis (EBE), a complication of systemic blood-stream infection, is a rare but dangerous threat to vision. Studies from different geographical regions have obtained different results on causative organisms in EBE: East Asian reports found that gram-negative organisms, especially Klebsiella pneumoniae, were the leading cause of EBE, while Western reports found that gram-positive organisms such as Staphylococcus aureus and Streptococcus pneumonia were more frequent [1-4]. Group B streptococcus (GBS; Streptococcus agalactiae), a gram-positive coccus that occasionally causes neonatal sepsis or invasive infection in the elderly, has been considered a rare cause of EBE, especially in East Asia. However, the number of invasive GBS infections is increasing, particularly in elderly patients with underlying conditions such as diabetes mellitus (DM), cardiovascular disease and cancer [5-8]. In the last 15 years, our affiliated institutions (Tohoku University Hospital and Gifu University Hospital), located in Japan, have seen at least 6 cases of EBE caused by GBS in elderly patients. Moreover, an online search revealed 10 more cases in Japan [9-18]. Thus, at least 35 cases of EBE caused by GBS in adults have been reported in English or Japanese [2, 9-33]. Although a variety of microorganisms cause EBE, we consider that GBS is one of the most important. Here, we examine the clinical characteristics of EBE caused by GBS, describe 6 cases we observed, and review relevant recent literature, including a comparison of East Asian and Western cases.

\section{Methods}

\section{Patients}

We retrospectively reviewed the records of 6 eyes of 6 patients with EBE caused by GBS, all of whom were observed at Tohoku University Hospital or Gifu University Hospital between December 2003 and September 2016. The diagnosis of EBE caused by GBS was based on positive results from culture testing of blood or ocular samples (either the aqueous humor or vitreous body) obtained from patients with iritis and vitritis during ophthalmic examination. Patients with a potential exogenous cause of infection, such as trauma, recent ocular surgery or corneal ulcer, were excluded. Clinical histories, including underlying medical conditions, initial symptoms, culture testing, infection foci, treatment and final visual acuity outcome were examined. Database searches were performed with Medline for articles in English and Google Scholar for articles in Japanese for the period ending in June 2019. Each search query included the terms "Group B streptococcus", "Streptococcus agalactiae" and "endogenous endophthalmitis". In Google Scholar, these Japanese equivalents for these terms were used. These searches identified 47 eyes of 35 patients with EBE caused by GBS (Medline: 36 eyes of 29 patients in 18 English articles, Google Scholar: 11 eyes of 6 patients in 6 Japanese articles). Thus, combined with the 6 eyes of 6 patients observed directly, this study retrospectively reviewed the records of 53 eyes of 41 patients.

\section{Microbiological studies}

At Tohoku University Hospital, isolated colonies on 5\% sheep blood agar plates were evaluated with matrixassisted laser desorption/ionization-time of flight mass spectrometry (MALDI-TOF MS) using the VITEK MS ver. 3.0 (bioMérieux, Marcy L'Étoile, France); this revealed that the colonies comprised Streptococcus agalactiae. At Gifu University Hospital, identification of GBS was performed with Gram staining, a catalase reaction, examination of colony morphology, hemolysis with a blood agar plate, and an examination for the Lancefield group B antigen. Susceptibility testing for antibiotics was performed with the microdilution method at both participating institutions. The MicroScan WalkAway 96 plus System (Beckman Coulter Inc., Brea, CA, USA) with a MICrofast7J panel was used at Tohoku University Hospital and the RAISUS system (Nissui Pharmaceutical Co., Ltd., Tokyo, Japan) with an NKMP1 plate was used at Gifu University Hospital. All results were interpreted according to the Clinical and Laboratory Standards Institute standard method.

\section{Statistical analysis}

Fisher's exact test was used to compare binary data. $P$ values $<0.05$ were considered statistically significant.

\section{Results}

\section{Observational case series}

A clinical summary of the 6 cases observed at our clinics is shown in Table 1 . The average age was 73.5 years. Every patient had unilateral endophthalmitis (3 left eyes and 3 right eyes). Four patients had DM. Three patients reported visual disturbance as the initial symptom, while the other three initially reported systemic symptoms, such as fatigue, anorexia and algor. The specialties of the initially consulted doctors were as follows: ophthalmologist (3 cases), physician (2 cases), and surgeon (1 case). The diagnosis of EBE caused by GBS was based on positive findings from blood culture testing in 5 of 6 cases. Culture testing of ocular samples was also performed in 3 of these 5 cases, with positive findings in 2 cases. One of 6 cases (case 4) had negative findings in blood culture testing, but had positive findings in ocular sample culture testing, leading us to diagnose EBE caused by GBS. The focus of the infection in the cases was as follows: urinary tract infection (UTI) (3 cases); cellulitis (2 cases); arthritis (1 case); peritonitis (1 case); catheter-associated 


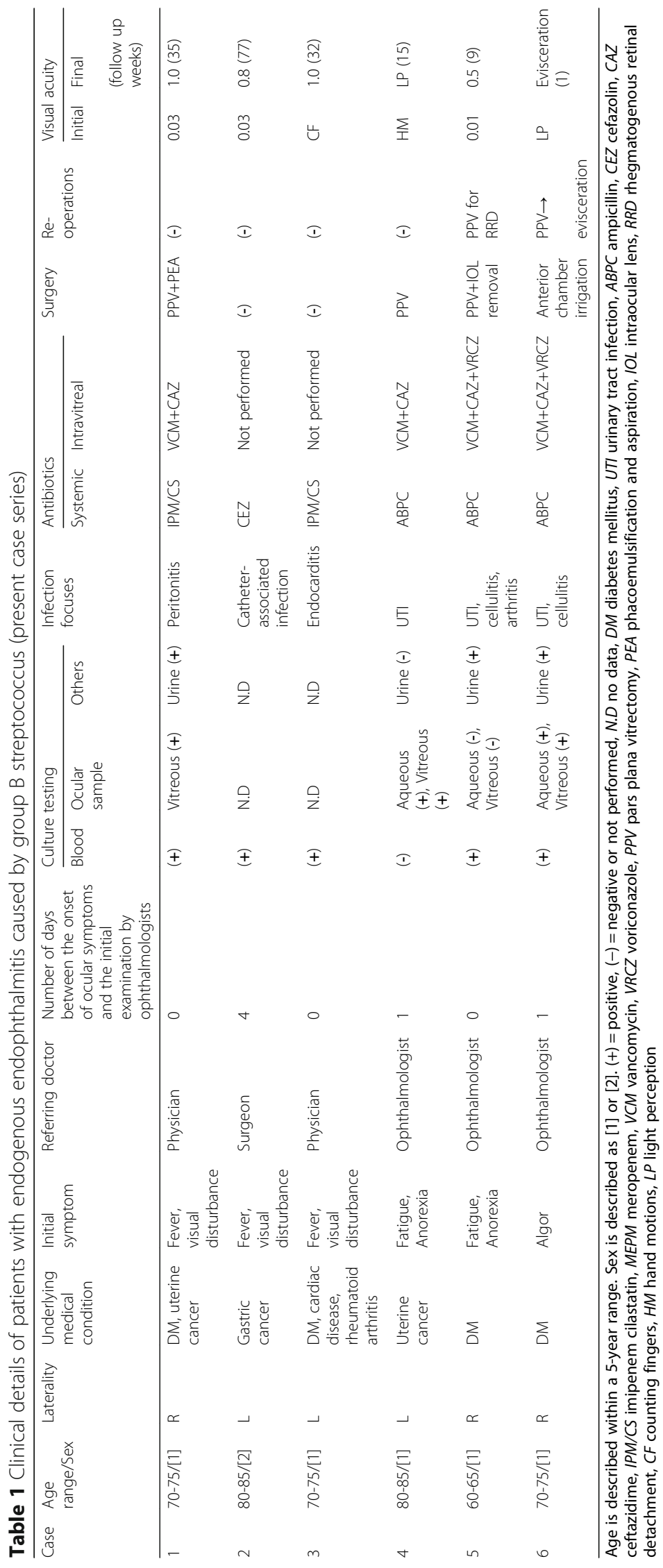


infection ( 1 case); and endocarditis (1 case). UTI and cellulitis co-occurred in 2 cases, and arthritis additionally co-occurred in one of these 2 cases. Susceptibility testing used blood samples in all cases except for case 4, for which ocular samples were used (both aqueous and vitreous samples in this case returned the same result). Susceptibility testing revealed that all the strains of GBS in these patients were sensitive to $\beta$-lactam antibiotics (penicillins, cephems and carbapenems) and vancomycin. Each strain had varying susceptibility to other antibiotics, such as macrolides (erythromycin and clarithromycin), tetracyclines (minocycline), fluoroquinolone (levofloxacin) and aminoglycoside (arbekacin), although some data were unavailable, as shown in Table 2. Among them, 4 strains were resistant to levofloxacin (no data for 1 isolate). Vitrectomy was performed in 4 cases, including the intravitreal injection of antibiotics. In case 2, vitrectomy could not be performed due to a poor systemic condition. In case 3, the patient's condition improved with only systemic antibacterial therapy. Visual acuity recovered in 4 cases. In the other cases (cases 4 and 6), visual acuity did not recover even after vitrectomy.

\section{Literature review}

We reviewed 41 cases of EBE caused by GBS, including the 6 cases observed at our clinics. Twenty-two cases were from East Asia (16 cases from Japan, 5 cases from Singapore and 1 case from South Korea). The other 19 cases were from Western countries (11 cases from the

Table 2 Susceptibility test of antibiotics (Present case series)

\begin{tabular}{lllllll}
\hline Antibiotics/case & 1 & 2 & 3 & 4 & 5 & 6 \\
\hline Penicillin-G & $\mathrm{S}$ & $\mathrm{S}$ & $\mathrm{S}$ & $\mathrm{N} / \mathrm{A}$ & $\mathrm{S}$ & $\mathrm{S}$ \\
Ampicillin & $\mathrm{S}$ & $\mathrm{S}$ & $\mathrm{S}$ & $\mathrm{S}$ & $\mathrm{S}$ & $\mathrm{S}$ \\
Cefazolin & $\mathrm{N} / \mathrm{A}$ & $\mathrm{S}$ & $\mathrm{S}$ & $\mathrm{S}$ & $\mathrm{N} / \mathrm{A}$ & $\mathrm{N} / \mathrm{A}$ \\
Ceftriaxone & $\mathrm{S}$ & $\mathrm{N} / \mathrm{A}$ & $\mathrm{S}$ & $\mathrm{S}$ & $\mathrm{S}$ & $\mathrm{S}$ \\
Meropenem & $\mathrm{N} / \mathrm{A}$ & $\mathrm{S}$ & $\mathrm{S}$ & $\mathrm{N} / \mathrm{A}$ & $\mathrm{S}$ & $\mathrm{S}$ \\
Imipenem & $\mathrm{S}$ & $\mathrm{S}$ & $\mathrm{S}$ & $\mathrm{S}$ & $\mathrm{N} / \mathrm{A}$ & $\mathrm{N} / \mathrm{A}$ \\
Vancomycin & $\mathrm{N} / \mathrm{A}$ & $\mathrm{S}$ & $\mathrm{S}$ & $\mathrm{S}$ & $\mathrm{S}$ & $\mathrm{S}$ \\
Erythromycin & $\mathrm{S}$ & $\mathrm{N} / \mathrm{A}$ & $\mathrm{N} / \mathrm{A}$ & $\mathrm{N} / \mathrm{A}$ & $\mathrm{S}$ & $\mathrm{S}$ \\
Clarithromycin & $\mathrm{N} / \mathrm{A}$ & $\mathrm{S}$ & $\mathrm{R}$ & $\mathrm{N} / \mathrm{A}$ & $\mathrm{S}$ & $\mathrm{N} / \mathrm{A}$ \\
Clindamycin & $\mathrm{N} / \mathrm{A}$ & $\mathrm{S}$ & $\mathrm{R}$ & $\mathrm{S}$ & $\mathrm{S}$ & $\mathrm{S}$ \\
Minocycline & $\mathrm{N} / \mathrm{A}$ & $\mathrm{S}$ & $\mathrm{I}$ & $\mathrm{R}$ & $\mathrm{N} / \mathrm{A}$ & $\mathrm{S}$ \\
Arbekacin & $\mathrm{N} / \mathrm{A}$ & $\mathrm{R}$ & $\mathrm{R}$ & $\mathrm{N} / \mathrm{A}$ & $\mathrm{NA}$ & $\mathrm{NA}$ \\
Levofloxacin & $\mathrm{R}$ & $\mathrm{N} / \mathrm{A}$ & $\mathrm{R}$ & $\mathrm{S}$ & $\mathrm{R}$ & $\mathrm{R}$ \\
\hline S Senstive, R & $\mathrm{S}$ & $\mathrm{S}$ & $\mathrm{S}$
\end{tabular}

$S$ Sensitive, $R$ Resistant, I Intermediate, N/A Not available

A susceptibility test of antibiotics was performed with the microdilution method at each facility. All results were interpreted according to the Clinical and Laboratory Standards Institute standard method.

Susceptibility testing used blood samples in all cases except for case 4 , for which ocular samples were used (both aqueous and vitreous samples in this case returned the same result)
United States, 5 cases from the United Kingdom, 2 cases from Canada and 1 case from Spain). The 41 cases included 21 men, 18 women and 2 cases with unstated sex. The average age was 65.5 years (SD: 12.7 ; range: $42-$ 95 years). In 29 patients (71\%), EBE was unilateral: 16 cases $(55 \%)$ in the right eye, $11(38 \%)$ cases in the left eye, and unstated in $2(7 \%)$ cases. Twelve patients $(29 \%)$ had bilateral EBE. Visual acuity (initial and final) in the 43 eyes of 34 patients for whom these data were available is shown in Fig. 1. Of these 43 eyes, 24 eyes of 19 patients were from East Asia and 19 eyes of 14 patients were from Western countries. Twenty-six eyes $(60 \%)$ finally lost all vision or died (i.e., no light perception [NLP], phthisis bulbi, evisceration, enucleation or death). Seven eyes (16\%) achieved final visual acuities greater than 0.6 in decimal values. There was no significant difference in the visual acuity outcome between the cases from East Asia and Western countries. The group of subjects with a final outcome of loss of vision or death (including NLP, phthisis bulbi, evisceration, enucleation and death) had a significantly greater incidence of initial visual acuity of less than counting fingers (CF) (Table 3). Among the 15 cases that underwent vitrectomy, 10 cases had an initial visual acuity of less than CF. However, 7 of these 10 cases lost vision even after vitrectomy. This rate of vision loss was not significantly different than in the cases with initial visual acuity of less than CF that did not undergo vitrectomy (17/22 cases; $77 \%)$. Moreover, a patient age $\geq 80$ years at presentation was not associated with a final loss of vision (Table 3). Of 41 patients, $13(32 \%)$ had DM as an underlying medical

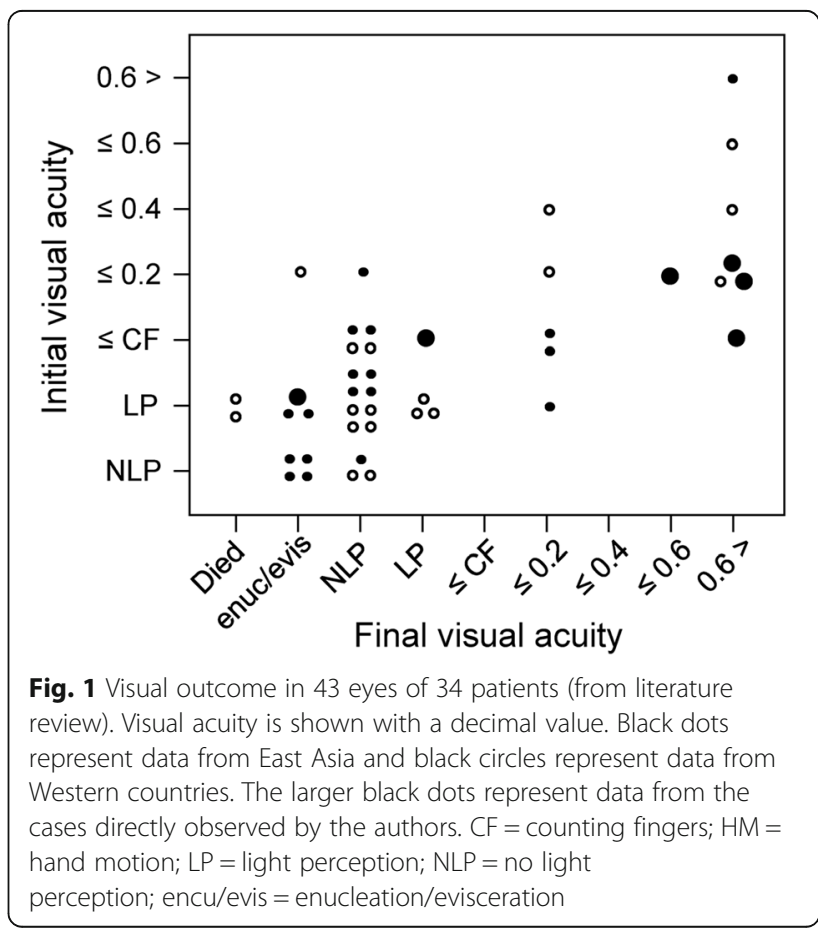


Table 3 Visual outcome and clinical background of 43 eyes (Literature review)

\begin{tabular}{llll}
\hline Parameters and history & \multicolumn{2}{l}{ Visual outcome } & $P$ value \\
\cline { 2 - 3 } & $\begin{array}{l}\text { Loss of vision } \\
N=26\end{array}$ & $\begin{array}{l}\text { More than LP } \\
N=17\end{array}$ & \\
\hline Age $\geq 80$ & $6 / 26(23 \%)$ & $3 / 17(18 \%)$ & NS \\
Initial visual acuity $\leq$ CF & $24 / 26(92 \%)$ & $8 / 17(47 \%)$ & 0.003 \\
\hline
\end{tabular}

Fisher's exact test

LP light perception, CF counting fingers, NS not significant

Loss of vision includes non-light perception, phthisis, evisceration, enucleation and death

condition. The second most common condition was human immunodeficiency virus infection (3 cases, 7\%). Extraocular infection foci are shown in Table 4. The most common focuses were as follows: endocarditis (15, $37 \%)$; arthritis (13, 32\%); cellulitis (8, 20\%); UTI (6, 15\%); pneumonia (4, 10\%); and meningitis (3, 7\%). These showed no significant differences in the cases from East Asia and Western countries. Of 41 patients, 17 (41\%) had infection foci in more than 3 organs (multiple infections in a single type of organ, such as joints or soft tissue, were counted as single foci).

\section{Discussion}

Our review showed that EBE caused by GBS has an extremely poor prognosis, including vision loss and even death (in 2 cases). Previous reports on invasive GBS infection in nonpregnant adults have also shown a poor prognosis, with a mortality rate as high as $8-24 \%[6,34,35]$. Nevertheless, visual acuity recovered in 4 of our 6 directly-observed cases, despite relatively poor initial visual acuity, reaching decimal visual acuity of more than 0.8

Table 4 Infection focuses of 41 cases (Literature review)

\begin{tabular}{llll}
\hline Focuses & $\begin{array}{l}\text { East Asia } \\
n=22\end{array}$ & $\begin{array}{l}\text { West } \\
n=19\end{array}$ & $\begin{array}{l}\text { Total } \\
n=41\end{array}$ \\
\hline Endocarditis & $6(27 \%)$ & $9(47 \%)$ & $15(37 \%)$ \\
Arthritis & $7(32 \%)$ & $6(32 \%)$ & $13(32 \%)$ \\
Cellulitis & $6(27 \%)$ & $2(11 \%)$ & $8(20 \%)$ \\
Urinary tract infection & $3(14 \%)$ & $3(16 \%)$ & $6(15 \%)$ \\
Pneumonia & $2(9 \%)$ & $2(11 \%)$ & $4(10 \%)$ \\
Meningitis & $1(5 \%)$ & $2(11 \%)$ & $3(7 \%)$ \\
Osteomyelitis & $2(9 \%)$ & 0 & $2(5 \%)$ \\
Periodontitis & $2(9 \%)$ & 0 & $2(5 \%)$ \\
Pharyngitis & 0 & $2(11 \%)$ & $2(5 \%)$ \\
Peritonitis & $1(5 \%)$ & 0 & $1(2 \%)$ \\
Cervical epidural abscess & $1(5 \%)$ & 0 & $1(2 \%)$ \\
Catheter-associated infection & $1(5 \%)$ & 0 & $1(2 \%)$ \\
Diverticulitis & 0 & $1(5 \%)$ & $1(2 \%)$ \\
Endoarteritis & 0 & $1(5 \%)$ & $1(2 \%)$ \\
Unknown & 0 & $1(5 \%)$ & $1(2 \%)$ \\
\hline
\end{tabular}

in 3 cases. Although a review of 41 cases showed that poor initial visual acuity (less than $\mathrm{CF}$ ) was significantly associated with a final complete loss of vision, no other clinical characteristics, such as surgical intervention with vitrectomy surgery or age, were predictive of outcome. We also investigated various clinical background factors, such as underlying medical conditions, initial symptoms, the type of referring doctor, the number of days between the onset of ocular symptoms and the initial examination by ophthalmologists, the use of intravitreally injected antibiotics, age, and surgical intervention, but none of these factors were associated with the favourable outcomes we observed. Some reports found differing mortality rates with the differing serotype of the strain of GBS [34, 35]. We did not investigate the serotype of the GBS strains in the current case series, but the differing virulence of each GBS strain might have affected the prognosis, which could explain our finding that some cases had good outcomes despite poor initial visual acuity.

Susceptibility testing of the isolated GBS strains in the 6 directly-observed cases showed that all 6 strains were sensitive to $\beta$-lactams (penicillins and cephems) and vancomycin (no data for 1 isolate) and 4 strains were resistant to levofloxacin (no data for 1 isolate). GBS isolates highly resistant to quinolones were first reported in Japan in 2003, followed by reports from other countries $[6,36-39]$. While quinolone-resistant GBS is common in Japan (40.2\%) and Korea (32.7\%), it is rare (0.9 to $4.8 \%)$ in other countries $[35,40]$. Overuse of quinolone in Japan might have increased the incidence of quinolone-resistant GBS [41]. Thus, intravitreal injection with a combination of vancomycin and ceftazidime, which is commonly used as an empirical treatment before a definite diagnosis, may be a good choice for treating EBE caused by GBS, even before the causative microorganism is identified. As for systemic treatment, although penicillins are usually good choices, the largest case study of adult invasive GBS infection in Japan reported that 9 of 443 (2\%) isolate GBS strains had reduced penicillin susceptibility [35], and there has been a report of invasive vancomycin-resistant GBS [42]. Awareness of resistant strains is thus important.

In the current review, the most common non-ocular infection focus was endocarditis (37\%) while previous research on invasive GBS infection showed that endocarditis was not a common infection focus [43]. This discrepancy may be due to overestimation caused by selection bias, because endocarditis is severe, and thus more likely to be reported. Nevertheless, the high rate described in the current study is noteworthy, because the mortality rate of endocarditis caused by GBS has been reported to be as high as $40 \%$ [44]. The diagnosis of endocarditis requires echocardiography, but the current case series showed significant variation in initial 
symptoms and the medical field of the first doctor consulted. Thus, it is important for all types of doctors, even ophthalmologists, to consider the possibility of endocarditis on encountering EBE, especially caused by GBS, and to obtain adequate consultation from specialists.

\section{Conclusions}

The past literature has generally reported that EBE caused by GBS is a severe condition with a poor prognosis, especially when initial visual acuity is low, and that loss of vision is common, even after vitrectomy. Nevertheless, 4 of the 6 patients at our clinic had relatively good outcomes, despite low initial visual acuity. Although we cannot confidently speculate why this was so, our results show that good outcomes may still be possible in severe cases, and that every effort should be made to ensure prompt and accurate diagnosis and treatment. Furthermore, our current case series and literature review demonstrates that DM is common in patients with EBE caused by GBS. Finally, the current review highlights that it is important for clinicians to consider the possibility of endocarditis when they encounter EBE, especially when caused by GBS.

\section{Abbreviations \\ GBS: Group B streptococcus; EBE: Endogenous bacterial endophthalmitis; DM: Diabetes mellitus; UTI: Urinary tract infection; NLP: No light perception; CF: Counting fingers}

\section{Acknowledgements}

The authors thank Prof. Hiroshige Mikamo and Mr. Makoto Katsumi for laboratory assistance and Mr. Tim Hilts for reviewing this manuscript.

\section{Authors' contributions}

MY was a major contributor to the drafting of the manuscript. SY and [TN]2 reviewed and edited the manuscript. [TN]1, [KM]1, and TS acquired the clinical data. [KM]2, TO, KN, and HK were responsible for the interpretation of results. All authors read and approved the final manuscript.

\section{Funding}

There was no funding or grant support.

\section{Availability of data and materials}

All data are presented in the manuscript, figure, and tables.

\section{Ethics approval and consent to participate}

The study was approved by the Institutional Review Boards (IRB) of Tohoku University Hospital (2017-1-553) and Gifu University Hospital (29-347) and was conducted in accordance with the tenets of the Declaration of Helsinki. The need for consent to participate was waived by the appropriate IRB as the study was retrospective. Instead of obtaining written informed consent, information on the purpose and implementation of the research was released on the website of Tohoku University Graduate School of Medicine and Gifu University School of Medicine. The IRBs of the facilities approved this procedure.

\section{Consent for publication}

In lieu of obtaining consent for publication from the subjects, identifying data, such as age and sex, were anonymized.

\section{Competing interests}

Author Kazuichi Maruyama is an Editorial Board Member for the BMC Series.

\section{Author details}

'Department of Ophthalmology, Tohoku University Graduate School of Medicine, 1-1, Seiryo-machi, Aoba-ku, Sendai, Miyagi 980-8574, Japan. ${ }^{2}$ Department of Ophthalmology, Gifu University Graduate School of Medicine, Gifu, Japan. ${ }^{3}$ Department of Ophthalmology, School of Medicine, Toho University, Tokyo, Japan. ${ }^{4}$ Department of Advanced Ophthalmic Medicine, Tohoku University Graduate School of Medicine, Sendai, Japan. ${ }^{5}$ Department of Retinal Disease Control, Tohoku University Graduate School of Medicine, Sendai, Japan. ${ }^{6}$ Department of Ophthalmic Imaging and Information Analytics, Tohoku University Graduate School of Medicine, Sendai, Japan.

Received: 31 July 2019 Accepted: 9 March 2020

Published online: 31 March 2020

\section{References}

1. Wong JS, Chan TK, Lee HM, Chee SP. Endogenous bacterial endophthalmitis: an east Asian experience and a reappraisal of a severe ocular affliction. Ophthalmology. 2000;107:1483-91.

2. Okada AA, Johnson RP, Liles WC, D'Amico DJ, Baker AS. Endogenous bacterial endophthalmitis. Report of a ten-year retrospective study. Ophthalmology. 1994;101:832-8.

3. Jackson TL, Eykyn SJ, Graham EM, Stanford MR. Endogenous bacterial endophthalmitis: a 17-year prospective series and review of 267 reported cases. Surv Ophthalmol. 2003;48:403-23.

4. Todokoro D, Mochizuki K, Nishida T, Eguchi H, Miyamoto T, Hattori T, et al. Isolates and antibiotic susceptibilities of endogenous bacterial endophthalmitis: a retrospective multicenter study in Japan. J Infect Chemother. 2018;24:458-62.

5. Lamagni TL, Keshishian C, Efstratiou A, Guy R, Henderson KL, Broughton K, et al. Emerging trends in the epidemiology of invasive group $B$ streptococcal disease in England and Wales, 1991-2010. Clin Infect Dis. 2013; 57:682-8.

6. Skoff TH, Farley MM, Petit S, Craig AS, Schaffner W, Gershman K, et al. Increasing burden of invasive group B streptococcal disease in nonpregnant adults, 1990-2007. Clin Infect Dis. 2009;49:85-92.

7. Ballard MS, Schønheyder HC, Knudsen JD, Lyytikäinen O, Dryden M, Kennedy KJ, et al. The changing epidemiology of group B streptococcus bloodstream infection: a multi-national population-based assessment. Infect Dis (London, England). 2016;48:386-91.

8. Björnsdóttir ES, Martins ER, Erlendsdóttir H, Haraldsson G, Melo-Cristino J, Kristinsson KG, et al. Changing epidemiology of group B streptococcal infections among adults in Iceland: 1975-2014. Clin Microbiol Infect. 2016. 22:379.e9-379.e16.

9. Matsuo K, Nakatuka K, Yano Y, Fujishima W, Kashima K. Group B streptococcal metastatic endophthalmitis in an elderly man without predisposing illness. Jpn J Ophthalmol. 1998;42:304-7.

10. Sakai T, Kohzaki K, Watanabe A, Tsuneoka H, Shimadzu M. Use of DNA microarray analysis in diagnosis of bacterial and fungal endophthalmitis. Clin Ophthalmol. 2012;6:321-6.

11. Sugita K, Tanabe T, Arima N, Saito I. Endogenous endophthalmitis in a case with group B Streptococcus endocarditis. Rinsho Ganka. 2011;65:1955-61.

12. Nakatsuka A, Azegami C, Kobayashi H, Kurita H, Kurashina K. A case of endophthalmitis caused by an oral bacterium. J Japanese Stomatol Soc. 2003;52:23-5.

13. Takamoto Y, Kunitomo R, Sassa T, Sakaguchi H, Hagiwara S, Moriyama S, et al. A case of infective endocarditis in which surgical removal of both eyes was inevitable because of bacterial Endopthalmitis. Japanese J Cardiovasc Surg. 2007;36:348-51.

14. Kobayashi K, Fujiseki Y, Takahashi K, Matsumura M. Bacterial Endopathalmitis caused by B Streptococcus endocarditis. Nihon Ganka Gakkai Zasshi. 2006; 110:199-204.

15. Nakamura H, Kinjyo S, Kaneshima H, Fujita J. A case of group B streptococcus endogenous endophthalmitis in elderly man with diabetes mellitus. J Japanese Assoc Infect Dis. 2006:80:267-70.

16. Murase $Y$, Yoshimoto $S$, Ueda K, Noto M. A case of diabetic patient with group B streptococcal metastatic endophthalmitis. J Japan Diabetes Soc. 1999:42:215-9.

17. Aoyama $Y$, Oba $Y$, Hoshide $S$, Arai $Y$, Komori T, Kabutoya $T$, et al. The early diagnosis of Endophthalmitis due to group B Streptococcus infective 
endocarditis and its clinical course: a case report and literature review. Intern Med. 2019;58:1295-9.

18. Nakai T, Kimura M, Yoshiyama K, Matono T. Endogenous endophthalmitis caused by Streptococcus agalactiae: an ophthalmologic emergency. IDCases. 2019;15:e00499.

19. Farber BP, Weinbaum DL, Dummer JS. Metastatic bacterial endophthalmitis. Arch Intern Med. 1985;145:62-4

20. O'Brart DP, Eykyn SJ. Septicaemic infection with group B streptococci presenting with endophthalmitis in adults. Eye (Lond). 1992;6(Pt 4):396-9.

21. Galloway A, Deighton CM, Deady J, Marticorena IF, Efstratiou A. Type V group B streptococcal septicaemia with bilateral endophthalmitis and septic arthritis. Lancet (London, England). 1993;341:960-1.

22. Ing EB, Erasmus MJ, Chisholm LD. Metastatic group B streptococcal endophthalmitis from a cutaneous foot ulcer. Can J Ophthalmol. 1993;28: 238-40.

23. Nagelberg HP, Petashnick DE, To KW, Woodcome HA. Group B streptococcal metastatic endophthalmitis. Am J Ophthalmol. 1994;117:498-500.

24. Buglass TD, Romanchuk KG. Fatal case of group B streptococcal endogenous endophthalmitis. Can J Ophthalmol. 1995;30:149-50.

25. Siddiqui MA, Lester RM. Septic arthritis and bilateral endogenous endophthalmitis associated with percutaneous transluminal coronary angioplasty. J Am Geriatr Soc. 1996;44:476-7.

26. Rosón B, Carratalà J, Peña C, Gudiol F. Endogenous endophthalmitis due to Streptococcus agalactiae: case report and revie. Clin Microbiol Infect. 1996;2: 147-9.

27. Lee S-Y, Chee S-P. Group B Streptococcus endogenous endophthalmitis : case reports and review of the literature. Ophthalmology. 2002;109:1879-86.

28. Pokharel D, Doan AP, Lee AG. Group B streptococcus endogenous endophthalmitis presenting as septic arthritis and a homonymous hemianopsia due to embolic stroke. Am J Ophthalmol. 2004;138:300-2.

29. Chihara S, Siccion E. Group B streptococcus endocarditis with endophthalmitis. Mayo Clin Proc. 2005;80:74.

30. Gupta SR, Agnani S, Tehrani S, Yeh S, Lauer AK, Suhler EB. Endogenous Streptococcus agalactiae (group B Streptococcus) endophthalmitis as a presenting sign of precursor T-cell lymphoblastic leukemia. Arch Ophthalmol. 2010;128:384-5.

31. Saffra N, Rakhamimov A, Husney R, Ghitan M. Streptococcus agalactiae endogenous endophthalmitis. BMJ Case Rep. 2013;2013:pii:bcr2013008981

32. Wu Z, Huang J, Huynh S, Sadda S. Bilateral endogenous endophthalmitis secondary to group B streptococcal sepsis. Chin Med J (Engl). 2014;127:1999.

33. Sim YR, Lee YJ, Park SW, Kim SH, Choi JH, Choi JY, et al. Infective endocarditis presenting as endogenous endophthalmitis secondary to Streptococcus agalactiae in a healthy adult: case report and literature review. Infect Chemother. 2017:49:286-92.

34. Phares CR, Lynfield R, Farley MM, Mohle-Boetani J, Harrison LH, Petit S, et al. Epidemiology of invasive group B streptococcal disease in the United States, 1999-2005. JAMA. 2008;299:2056-65.

35. Morozumi M, Wajima T, Takata M, Iwata S, Ubukata K. Molecular characteristics of group B streptococci isolated from adults with invasive infections in Japan. J Clin Microbiol. 2016;54:2695-700.

36. Kawamura Y, Fujiwara H, Mishima N, Tanaka Y, Tanimoto A, Ikawa S, et al. First Streptococcus agalactiae isolates highly resistant to quinolones, with point mutations in gyrA and parC. Antimicrob Agents Chemother. 2003;47: 3605-9

37. Faccone D, Guerriero L, Méndez E, Errecalde L, Cano H, Yoyas N, et al. Fluoroquinolone-resistant Streptococcus agalactiae isolates from Argentina. Rev Argent Microbiol. 2010:42:203-7.

38. Piccinelli G, Gargiulo F, Corbellini S, Ravizzola G, Bonfanti C, Caruso A, et al. Emergence of the first levofloxacin-resistant strains of streptococcus agalactiae isolated in Italy. Antimicrob Agents Chemother. 2015;59:2466-9.

39. Wang $Y-H$, Chen $C-L$, Hou J-N, Wang Y-R, Lin T-Y, Wang M-H, et al. Serotype distribution and resistance genes associated with macrolide and fluoroquinolone resistance in Streptococcus agalactiae isolates from a hospital in southern Taiwan. Biom J. 2015;38:215-20.

40. Ryu H, Park YJ, Kim YK, Chang J, yun YJK. Dominance of clonal complex 10 among the levofloxacin-resistant Streptococcus agalactiae isolated from bacteremic patients in a Korean hospital. J Infect Chemother. 2014;20:509-11.

41. Muraki Y, Kitamura M, Maeda Y, Kitahara T, Mori T, Ikeue H, et al. Nationwide surveillance of antimicrobial consumption and resistance to Pseudomonas aeruginosa isolates at 203 Japanese hospitals in 2010. Infection. 2013:41: 415-23.
42. Park C, Nichols M, Schrag SJ. Two cases of invasive vancomycin-resistant group B streptococcus infection. N Engl J Med. 2014;370:885-6.

43. High KP, Edwards MS, Baker CJ. Group B streptococcal infections in elderly adults. Clin Infect Dis. 2005:41:839-47.

44. Sambola A, Miro JM, Tornos MP, Almirante B, Moreno-Torrico A, Gurgui M, et al. Streptococcus agalactiae infective endocarditis: analysis of 30 cases and review of the literature, 1962-1998. Clin Infect Dis. 2002;34:1576-84.

\section{Publisher's Note}

Springer Nature remains neutral with regard to jurisdictional claims in published maps and institutional affiliations.
Ready to submit your research? Choose BMC and benefit from:

- fast, convenient online submission

- thorough peer review by experienced researchers in your field

- rapid publication on acceptance

- support for research data, including large and complex data types

- gold Open Access which fosters wider collaboration and increased citations

- maximum visibility for your research: over $100 \mathrm{M}$ website views per year

At BMC, research is always in progress.

Learn more biomedcentral.com/submissions 